\title{
A Facile and Efficient Method for the Debromination of vic-Dibromides to Alkenes with $\mathrm{BiCl}_{3} /$ Indium System
}

\author{
Byung Woo Yoo, ${ }^{*}$ Jong Ho Kim, and Min Hye Yang \\ Department of Advanced Materials Chemistry, Korea University, Jochiwon, Chungnam 339-700, Korea \\ ${ }^{*}$ E-mail:bwyoo@korea.ac.kr \\ Received September 22, 2009, Accepted February 3, 2010
}

Key Words: Debromination, Alkene, Bismuth, Indium

The vic-dibromide-alkene functional group interconversion represents a useful step in the double bond protection-deprotection strategy. ${ }^{1}$ To date, several protocols have been utilized for the debromination of vic-dibromides to alkenes, but some of these methods are associated with limitations regarding chemoselectivity, low yields, prolonged reaction times, and harsh reaction conditions. ${ }^{2}$ Consequently an efficient and mild procedure for debromination of vic-dibromides continues to be developed. The chemical reactivity of $\mathrm{BiCl}_{3} / \mathrm{M}$ system $(\mathrm{M}=\mathrm{Zn}$, $\mathrm{Fe}, \mathrm{Al}, \mathrm{Mg}$ ) has been the subject of considerable interest and the reducing ability of these systems has been extensively studied. ${ }^{3}$ Because of the close resemblance of indium to zinc in several respects, including first ionization, we reasoned that $\mathrm{BiCl}_{3}$ /indium system could serve as a protocol for the debromination of vic-dibromides. In recent years indium metal has drawn an increasing attention for its unique properties such as low toxicity and high stability in water and air compared with other metals. ${ }^{4}$ Bismuth(III) chloride is inexpensive, relatively non-toxic, fairly water insensitive, and environmentally benign reagent, which have been used as mild Lewis acid catalyst for synthetic transformations. In continuation to our interest in exploring the utility of metal-metal salt system in organic synthesis, ${ }^{5}$ we wish to report here an efficient and mild method for debromination of vic-dibromides $\mathbf{1}$ to alkenes $\mathbf{2}$ with $\mathrm{BiCl}_{3} /$ indium system in methanol at room temperature. The reaction can be generalized as in eq. 1. ${ }^{6}$ The new reagent system was generated by the addition of indium powder to a stirred solution of bismuth chloride in methanol under sonication. ${ }^{7}$ To guage the scope and limitations of this methodology, various substituted vic-dibromides were subjected to this protocal at room temperature. We have found that vic-dibromides on treatment with $\mathrm{BiCl}_{3} /$ indium system in methanol solution are smoothly converted into the corresponding alkenes in high yields.

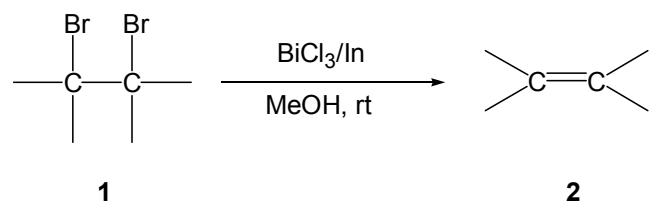

The high yields of the debromination products demonstrate the efficiency of this new method. To ensure the role of indium, a controlled experiment was carried out using vic-dibromides with $\mathrm{BiCl}_{3}$ without indium metal, which failed to yield any desired product. A $2: 1$ ratio of indium and $\mathrm{BiCl}_{3}$ was the best ratio in terms of yield and reaction time. And methanol has been found to be the most suitable solvent for the reaction.

Table 1. Reductive debromination of vic-dibromides with $\mathrm{BiCl}_{3} /$ indium system

(1)

${ }^{a}$ Isolated yields. The products are commercially available and were characterized by comparison of their spectral data with authentic samples. 
The result of the reaction is summarized in Table 1, where we examined a series of functionally and structurally various vicdibromides. Clearly a broad range of functional group (ester, carboxyl, aldehyde, methoxy, chloro, and ketone) was tolerated under the reaction conditions and only trans olefins were obtained. It was worth commenting that the sensitive carbonyl group remains intact without any further reduction under the reaction condition (entries 5-10). In comparison with other procedures, the present procedure reduced vic-dibromides in higher yields and showed a good chemoselectivity under mild conditions. The notable advantages of this methodology are mild reaction conditions, simple manipulation, high yields, and tolerance of various functional groups. No over-reduction of the produced alkene was observed with any substrate. ${ }^{8}$ Some of the vic-dibromides in the table are commercially available, or could be prepared conveniently from the corresponding precursors through known olefin halogenation reactions. ${ }^{9}$ Although the reaction mechanism is still not clearly understood at this time, the reaction can be envisaged to proceed in two stages. In the first bismuth(III) chloride is probably reduced by indium to form low-valent bismuth species, which in the subsequent step would debrominate vic-dibromides 1 to give the corresponding alkenes 2 through a SET (single electron transfer) process. The reducing property exhibited by metal-metal salt combinations proceeds through transfer of one electron from the metal surface to the substrate. In such combinations elementary metal part needs to be more electropositive than the metal part of the salt. The involvement of zero valent bismuth resulting from the transmetallation of bismuth chloride with indium metal may be presumed. ${ }^{10}$ We have been able to demonstrate the utility of $\mathrm{BiCl}_{3}$ /indium system for effecting chemoselective debromination of vic-dibromides.

In conclusion, we have demonstrated that $\mathrm{BiCl}_{3}$ /indium system mediates an efficient and mild conversion of vic-dibromides to the corresponding alkenes. Although the scope and limitations were not fully established, the present method could be a practical alternative to the conventional method. Further work on the application of $\mathrm{BiCl}_{3} /$ indium system is in progress.

Acknowledgments. This work was supported by Korea University Grant.

\section{References}

1. Greene, T. W.; Wuts, P. G. M. Protective Groups in Organic Synthesis, 2nd ed.; New York, 1991.

2. (a) Buther, T. S.; Detty, M. R. J. Org. Chem. 1998, 63, 169. (b) Li, C. J.; Harpp, D. N. Tetrahedron Lett. 1990, 31, 6291. (c) Malanga, C.; Mannucci, S.; Lardicci, L. Tetrahedron 1998, 54, 1021. (d) Tanata, R.; Negoro, N.; Yanada, K.; Fujita, T. Tetrahedron Lett. 1996, 37, 9313. (e) Ranu, B. C.; Guchhait, S. K.; Sarkar, A. Chem. Commun. 1998, 2113. (f) Mathai, M.; Sching, K.; Miller, S. I. J. Org. Chem. 1970, 35, 1733.

3. (a) Makoto, W.; Hidenori, O.; Kin-ya, A. Tetrahedron Lett. 1986, 27, 4771. (b) Zhen, S.; Jinqi, Z.; Huixian, Z.; Minmin, Y. Tetrahedron Lett. 1997, 38, 2733. (c) Makoto, W.; Tomohiro, F.; Mika, M.; Toshikazu, T.; Norikazu, M. Tetrahedron Lett. 1997, 38, 8045. (d) Norikazu, M.; Mami, N.; Shunsuke, M.; Tomohiro, F.; Makoto, W. Bull. Chem. Soc. Jpn. 2000, 73, 689 .

4. For review: (a) Nair, V.; Ros, S.; Jayan, C. N.; Pillia, B. S. Tetrahedron 2004, 60, 1959. (b) Lubineau, A.; Auge, J.; Queneau, Y. Synthesis 1994, 741. (c) Li, C. J. Tetrahedron 1996, 52, 5643. (d) Cintas, P. Synlett 1995, 1087.

5. (a) Han, J. H.; Choi, K. I.; Kim, J. H.; Yoon, C. M.; Yoo, B. W. Synth. Commun. 2006, 36, 415. (b) Yoo, B. W.; Song, M. S.; Park, M. C. Synth. Commun. 2007, 37, 3089. (c) Yoo, B. W.; Park, M. C.; Shin, J. I. Bull. Korean Chem. Soc. 2009, 30, 1927. (d) Yoo, B. W.; Choi, J. W.; Kim, Y. S. Bull. Korean Chem. Soc. 2008, 29, 1655.

6. A typical procedure for the debromination of vic-dibromides is as follows: Indium powder $(230 \mathrm{mg}, 2.0 \mathrm{mmol})$ and bismuth(III) chloride $(315 \mathrm{mg}, 1.0 \mathrm{mmol})$ were mixed in methanol $(4 \mathrm{~mL})$. The resulting mixture was stirred at room temperature for $0.5 \mathrm{hr}$ under sonication producing a solution of the low-valent bismuth-indium complex. 1,2-Dibromoethylbenzene ( $264 \mathrm{mg}, 1.0 \mathrm{mmol}$ ) was then added to this solution and the reaction mixture was stirred for 30 min at room temperature. The solvent was removed under reduced pressure and the residue was extracted with ether, washed with brine, and dried over anhydrous $\mathrm{Na}_{2} \mathrm{SO}_{4}$. The crude product was purified by silica gel column chromatography (hexane:ethyl acetate $=10: 1)$ to afford styrene $(99 \mathrm{mg}, 95 \%)$. All of the products are commercially available compounds, and their identification was based on spectral comparison with authentic samples.

7. Sonication were carried out in a BRANSONIC ultrasonic cleaner bath, which delivered a $47 \mathrm{KHz}$ wave, with a fixed electrical power of 125 Watts.

8. Hudlicky, T.; Sinai-Zingde, G.; Natchus, M. G. Tetrahedron Lett. 1987, 26, 5287.

9. Vogel's Textbook of Practical Organic Chemistry, 4th ed.; Longman Group Limited: 1978; London, p 400.

10. Petrier, C.; Barbosa, D.; Dupuy, C.; Luche, J. L. J. Org. Chem. 1985, 50, 5761 . 